\title{
Common polymorphisms in the cannabinoid CB2 receptor gene $(C N R 2)$ are not associated with myocardial infarction and cardiovascular risk factors
}

\author{
WIBKE REINHARD $^{1 *}$, KLAUS STARK ${ }^{1 *}$, KATHARINA NEUREUTHER $^{1}$, \\ KAMIL SEDLACEK $^{1}$, MARCUS FISCHER ${ }^{1}$, ANDREA BAESSLER ${ }^{1}$, STEFAN WEBER ${ }^{1}$, \\ BERNHARD KAESS ${ }^{1}$, SILKE WIEDMANN ${ }^{1}$, JEANETTE ERDMANN ${ }^{2}$, WOLFGANG LIEB ${ }^{2}$, \\ ANDREAS JERON $^{1}$, GUENTER RIEGGER ${ }^{1}$ and CHRISTIAN HENGSTENBERG ${ }^{1}$ \\ ${ }^{1}$ Klinik und Poliklinik für Innere Medizin II, Klinikum der Universität Regensburg, \\ Franz-Josef-Strauss-Allee 11, 93053 Regensburg; ${ }^{2}$ Medizinische Klinik II, Universitätsklinikum \\ Schleswig-Holstein, Campus Lübeck, Ratzeburger Allee 160, 23538 Lübeck, Germany
}

Received March 3, 2008; Accepted April 18, 2008

DOI: 10.3892/ijmm_00000004

\begin{abstract}
Myocardial infarction (MI) is a complex disease. Multiple genes and their interaction with various environmental factors influence the pathogenesis of MI that is thought to be tightly regulated by inflammatory pathways. Recent progress in genetic analysis includes the use of large-scale genomewide association studies that have proven to be powerful tools even in the analysis of multifactorial phenotypes. However, certain genes are only sparsely represented on the available gene chips and additional candidate gene approaches are necessary. One such example is the CNR2 gene, encoding the cannabinoid receptor 2 (CB2), which has been implicated in mediating anti-inflammatory and antiatherosclerotic effects in vivo. We therefore hypothesized that genetic variations within the CNR2 gene are associated with the development of MI or classic cardiovascular risk factors. In a large case-control study, 1,968 individuals from the German MI family study were examined with 13 single nucleotide polymorphisms (SNPs) covering CNR2 and the adjacent genes. The association of these SNPs with MI or cardiovascular risk factors, such as arterial hypertension, obesity, hypercholesterolemia and diabetes mellitus, was determined. In allelic and genotypic models, none of the SNPs showed a significant association with MI. Separate analyses for men and women revealed no gender-specific relationship between common genetic variations within the
\end{abstract}

Correspondence to: Dr Christian Hengstenberg, Klinik und Poliklinik für Innere Medizin II, Universitätsklinikum Regensburg, Franz-Josef-Strauss-Allee 11, 93053 Regensburg, Germany

E-mail: christian.hengstenberg@klinik.uni-regensburg.de

${ }^{*}$ Contributed equally

Key words: genetics, CNR2, myocardial infarction, cardiovascular risk factors, polymorphism
CNR2 gene and MI. Moreover, no significant association between $C N R 2$ gene variants and common cardiovascular risk factors was observed. We therefore provide evidence in a large German population that common polymorphisms within the $C N R 2$ gene confer no susceptibility to MI or to cardiovascular risk factors.

\section{Introduction}

Cardiovascular diseases continue to be the leading cause of death in high-income countries (1). Increasing evidence has emerged that inflammatory pathways play a key role in the pathogenesis of coronary artery disease (CAD) and other forms of atherosclerosis (2). CAD is regarded as a chronic inflammatory condition with its maximally exacerbated form of myocardial infarction (MI) following plaque rupture and thrombus formation $(2,3)$. Chronic medical treatment of cardiovascular disease is mainly based on the optimisation of concomitant cardiovascular risk factors, such as arterial hypertension and hypercholesterolemia. However, the direct challenge of the atherosclerotic lesions themselves is less addressed by pharmaceutical therapy. In contrast, statins have been reported to exert favourable pleiotropic properties by mediating anti-inflammatory and immunomodulatory effects (4). Other therapeutics that delay atherosclerotic disease progression, such as plaque stabilizers or immunosuppressants, are under development and intensive research for pharmaceuticals with anti-inflammatory properties is being carried out $(5,6)$.

Cannabinoids have been known for their anti-inflammatory and immunomodulatory potential for a long time $(7,8)$ and have been introduced in treating autoimmune disorders, such as multiple sclerosis or rheumatoid arthritis $(9,10)$. Recently, low dose oral cannabinoid treatment has been shown to reduce atherosclerosis progression in the apolipoprotein $\mathrm{E}$ knockout mouse model (11). The effects of inhibited macrophage chemotaxis and reduced lymphoid cell proliferation seem to be mediated via the cannabinoid 
receptor 2 (CB2) (12). CB2 is primarily expressed in cells of the immune system, such as $\mathrm{B}$ and $\mathrm{T}$ cells and monocytes $(12,13)$ and is found in human and mice atherosclerotic plaques (11). Its blockade by a selective antagonist completely reversed the anti-atherosclerotic effects in vivo (11) and, thus, it stands to reason that $\mathrm{CB} 2$ is involved in the pathogenesis of atherosclerosis.

These data qualify $C N R 2$ as a notable candidate gene for CAD. Moreover, recent genetic analyses implicated a common exonic $C N R 2$ gene polymorphism with systolic and diastolic blood pressure in Japanese men (14). However, CNR2 is not represented on the readily available genome-wide single nucleotide polymorphism (SNP) arrays (like Illumina Human Hap 300/550 Genotyping BeadChip and Affymetrix GeneChip Human Mapping $500 \mathrm{~K}$ array). HapMap data of the gene is scarce, thus a comprehensive analysis of the genomic region is warranted. Therefore, we evaluated 13 common genetic variations within and near the CNR2 gene concentrating on those with a possible impact on gene function. We assessed their association with MI and common cardiovascular risk factors carrying out a case-control association analysis in 1,968 individuals from the German MI family study.

\section{Materials and methods}

Study population. All MI patients were participants of the German MI family study. Selection criteria and study details were described previously $(15,16)$. In brief, we identified MI families from all parts of Germany with the accumulation of premature $\mathrm{MI}$ and/or severe $\mathrm{CAD}$, e.g. percutaneous coronary intervention or coronary bypass surgery. The index patient always suffered from MI before the age of 60 years. The diagnosis of MI was established by a review of medical records according to the MONICA (Monitoring trends and determinants in cardiovascular disease) diagnostic criteria (http://www.ktl.fi/publications/monica/manual/index.htm). Control individuals were recruited from unaffected spouses of MI family members who had no genetic relationship to the cases.

The present case-control study included 1,040 unrelated MI patients and 928 unrelated, unaffected control subjects (cardiovascular disease-free married-in spouses, sisters-in-law, and brothers-in-law). Individuals with a history of CAD, cerebrovascular accidents (transient ischemic attack or stroke) or peripheral artery disease were excluded from the control group. Written informed consent was obtained from each of the subjects and the local Ethics Committee approved the research protocol.

Definition of cardiovascular risk factors. Individuals with a systolic blood pressure $\geq 140 \mathrm{mmHg}$ or diastolic blood pressure $\geq 90 \mathrm{mmHg}$ or regular intake of established blood pressure lowering drugs (diuretics, $\beta$-blockers, angiotensin converting enzyme inhibitors, angiotensin 2-blockers, calcium channel blockers, vasodilators, $\alpha$-blockers) were classified as hypertensive. Individuals who reported a current or former smoking habit were classified as smokers. Hypercholesterolemia was defined as low density lipoprotein (LDL) cholesterol $\geq 160 \mathrm{mg} / \mathrm{dl}$ or use of lipid lowering therapy (statins, fibrates). Diabetes was defined as self-reported diabetes mellitus or the regular intake of anti-diabetic medication. Obesity was defined as a body mass index (BMI) $\geq 30 \mathrm{~kg} / \mathrm{m}^{2}$.

Phenotyping. At recruitment, each of the patients was studied with a standardized interview, clinical examination and biochemical as well as molecular analyses, as previously described (16-18). A validation of cardiovascular events at study entry was performed by a review of medical records. Resting blood pressure was taken according to the MONICA guidelines after participants had been resting in a sitting position (19). Body weight in kilograms and height in meters were determined with subjects wearing light clothing. Asservation of serum was carried out from non-fasting individuals. Serum levels of low- and high-density lipoprotein cholesterol were measured by standard enzymatic methods (20). Baseline characteristics of all the individuals are shown in Table I.

SNPs and genotyping methods. Among several polymorphisms previously identified within $C N R 2$, we focused on those with a possible impact on gene function and used an exon-centred approach in our SNP selection with a dense coverage of the coding second exon. Other selection criteria for the 13 SNPs were: i) minor allele frequency (MAF) of $>0.05$ in a Caucasian population according to HapMap Project http:// www.hapmap.org/ (21), ii) compatibility with our genotyping platform and iii) evidence of validation status. To determine the extent of LD beyond the boundaries of the gene, SNPs in the $5^{\prime}$ and $3^{\prime}$ flanking sequences and the neighbouring genes were included.

Genomic DNA was extracted from EDTA blood samples by standard procedures. Pre-designed and custom-made Taq Man ${ }^{\circledR}$ SNP genotyping assays (Applied Biosystems) were used (Table II). PCR reaction and post-PCR endpoint plate read was carried out according to the manufacturer's instructions using the Applied Biosystems 7900HT real-time PCR system. Sequence detection system software (SDS 2.2) was used to assign genotypes applying the allelic discrimination test performed by a person blinded to the affection status (22). Case and control DNA was genotyped together on the same plate. Duplicates of samples (15\%) were employed to assess intra-plate and inter-plate genotyping quality. There were no discrepancies between the duplicates. The overall genotyping call-rate was $>98 \%$ for all SNPs. For the association analyses, individuals with $<10 \%$ genotypes were excluded $(n=27)$; the genotyping rate in the remaining individuals was $99.8 \%$.

Statistical analyses. To determine whether the genotypes of cases and controls of all CNR2 SNPs deviated from the Hardy-Weinberg equilibrium, actual and predicted genotype counts of cases and controls were compared by the exact test (23). Differences in allele frequencies between the MI cases and the controls were analyzed employing the $\chi^{2}$-test. To account for an uneven distribution of baseline factors across genotypes, a logistic regression model with genotype, age and gender as explanatory variables was developed. Genotypes were coded for the dominant and recessive effect. Odds ratios (OR) with their $95 \%$ confidence intervals (CI) 






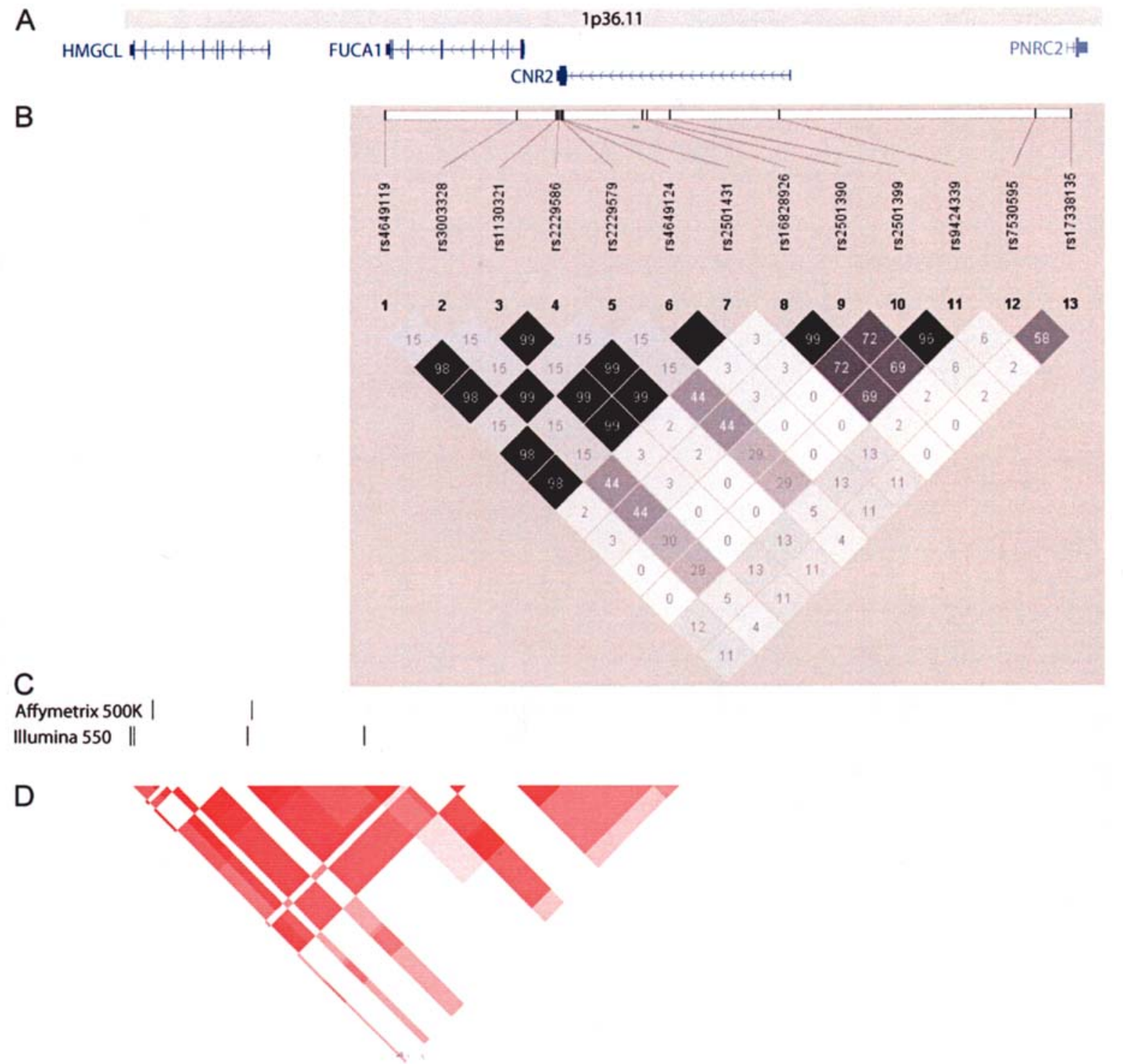

Figure 1. A schematic representation of the CNR2 gene locus and its LD pattern. (A) The $\sim 165$ kb genomic region on chromosome $1 \mathrm{p} 36.11$ contains $C N R 2$ and neighbouring genes (HMGCL, 3-hydroxylmethyl-3-methylglutaryl-Coenzyme A; FUCA1, $\alpha$-L fucosidase; PNRC2, proline-rich nuclear receptor co-activator 2). $C N R 2$ is oriented from right to left. Horizontal lines correspond to introns and vertical bars depicting the exons. (B) Distribution of the 13 genotyped SNPs and representation of LD structure in the $C N R 2$ region. Pairwise $r^{2}$-values (multiplied by 100 ) between markers are shown. Black denotes perfect LD with $\mathrm{r}^{2}=1$; white denotes no LD with $r^{2}=0$; grey denotes $r^{2}$ intermediate LD between 0 and 1 . Note that there is a region of strong LD between SNPs rs4649119 and rs 2501431 including the CNR2 coding region. (C) Coverage of depicted genomic region with the SNP marker from common genome-wide SNP arrays. SNP markers represented on the Affymetrix GeneChip Human Mapping $500 \mathrm{~K}$ array set and Illumina HumanHap 550 Genotyping BeadChip are shown as vertical lines. Note that no array SNP marker is present in the CNR2 gene. (D) LD structure from HapMap phase II data (release 21).

from the Wald $\chi^{2}$-test are reported. A two-sided P-value of $<0.05$ indicated statistical significance.

Furthermore, associations between CNR2 SNPs and cardiovascular risk factors were analysed employing the $\chi^{2}$-test for differences in allele frequencies. Risk factors were treated as qualitative traits with either the presence or absence of the appropriate risk factor definition. To test for the association of rs2501431 and arterial hypertension, additional analyses were performed. Blood pressure levels between the three genotypes were compared by a one-way analysis of variance and the Turkey-HSD post hoc test. Descriptive P-values of a 2-tailed t-test for independent samples are reported for the dominant $(\mathrm{GG}+\mathrm{AG}$ vs. AA) and recessive (GG vs. AA + AG) model. Moreover, logistic regression models for a dominant and recessive effect on the prevalence of hypertension with adjustment for age, gender and anti-hypertensive therapy were performed. Analyses were carried out using JMP IN 5.1 (SAS Institute Inc., Cary, NC, USA), SPSS 15.0 (SPSS Inc., Chicago, IL, USA) and plink v0.99s (24).

LD structure in the CNR2 region was determined from pairwise $\mathrm{r}^{2}$-values between markers calculated with the program Haploview (http://www.broad.mit.edu/mpg/ haploview (25).

\section{Results}

Association analyses of CNR2 variants with MI. The CNR2 gene consists of two exons, whereby only exon 2 translates into the CB2 protein. We genotyped 13 SNPs covering a region of $\sim 120 \mathrm{~kb}$ focusing on $C N R 2$ exon 2 and including six SNPs 


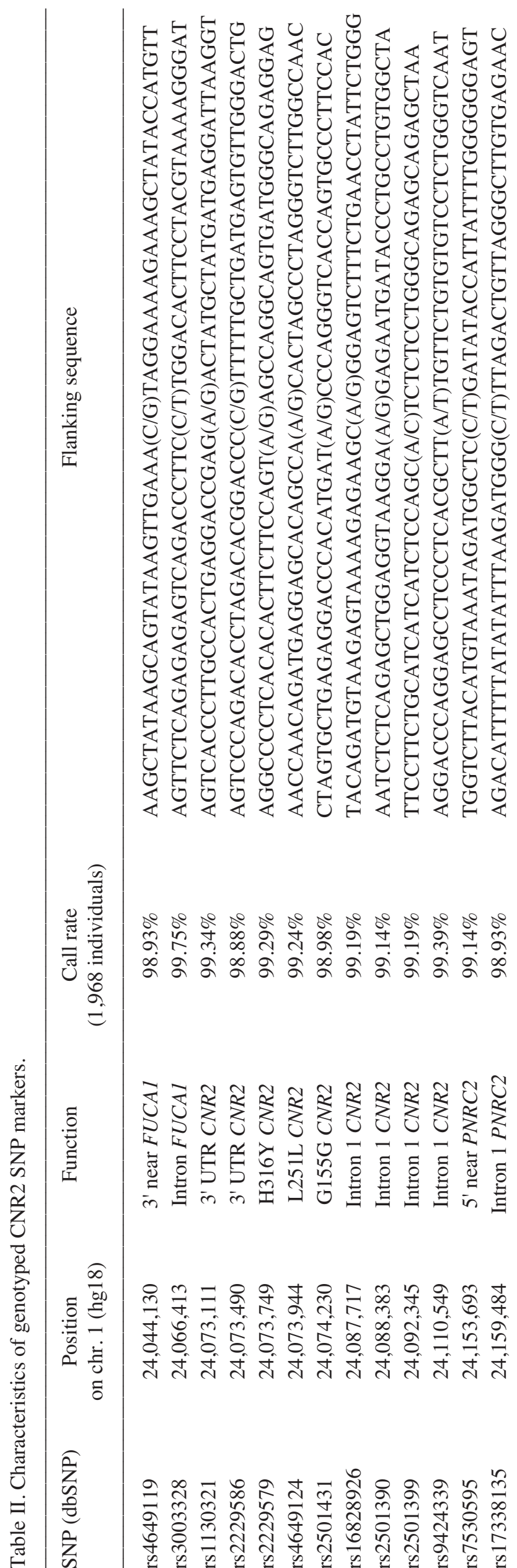

encompassing the $3^{\prime}$ and 5' UTR and neighbouring genes (Fig. 1, Table II). All of the 13 SNPs met the Hardy-Weinberg expectations $(\mathrm{P}=0.05$ level, exact test). Strong linkage disequilibrium (LD) was present between SNPs rs4649119 and rs2501431 including the CNR2 coding region as previously shown by Karsak et al and supported by HapMap data (Fig. 1) $(21,26)$.

We found no statistically significant differences of allele and genotype distributions between the MI cases and the controls (Table III). Likewise, no significant association between the 13 CNR2 SNPs and MI was observed in the dominant and recessive genetic model (Table III). To test for gender-specific influences of CNR2 variants on MI, we performed analyses in men and women separately, where no gender-specific effects could be detected (data not shown).

Association analyses of CNR2 variants with cardiovascular risk factors. We investigated whether the CNR2 variants conferred susceptibility to classic CAD related risk factors such as obesity, arterial hypertension, hypercholesterolemia and diabetes mellitus.

A comparison of the allele frequencies between the individuals with and without the respective quantitative trait showed no significant effect of the CNR2 variants on the prevalence of obesity, arterial hypertension and diabetes mellitus (Table IV). Only hypercholesterolemia displayed a marginal significant association with rs3003328 $(\mathrm{P}=0.045)$ and rs2229586 $(\mathrm{P}=0.044)$. However, the two SNPs are in strong LD $\left(r^{2}=0.997\right)$ and the two have a relatively low MAF (for rs3003328 and rs2229586 in cases and controls 0.097 and 0.109 as well as 0.096 and 0.107 , respectively).

In particular, rs2501431, previously shown to be associated with blood pressure levels in Japanese men (14), displayed in our study population no significant difference in the prevalence of arterial hypertension dependent on the genotype (Table V). The exclusion of individuals with anti-hypertensive medication or adjustment for medication intake, age and gender in a logistic regression model did not influence this finding (Table V). Moreover, systolic or diastolic blood pressure levels were not significantly influenced by the rs2501431 variant regardless of whether a comparison of the genotypes applied or a dominant or recessive model was assumed (Table V).

\section{Discussion}

In recent years, increasing evidence has been presented highlighting the role of inflammation in the pathogenesis of atherosclerosis and its complications (2). The early atherosclerotic lesions are dominated by immune cells and disease progression is accelerated by their effector molecules (3). The cannabinoids are well recognized for their anti-inflammatory properties (8). Recently, CB2 was found in human atherosclerotic plaques, where it exhibited clear anti-atherosclerotic effects (11) and therefore represents a good candidate gene for CAD.

In the present case-control association study, we comprehensively evaluated the relationship of 13 common genetic variations within the CNR2 gene with MI and their potential influence on the established cardiovascular risk 


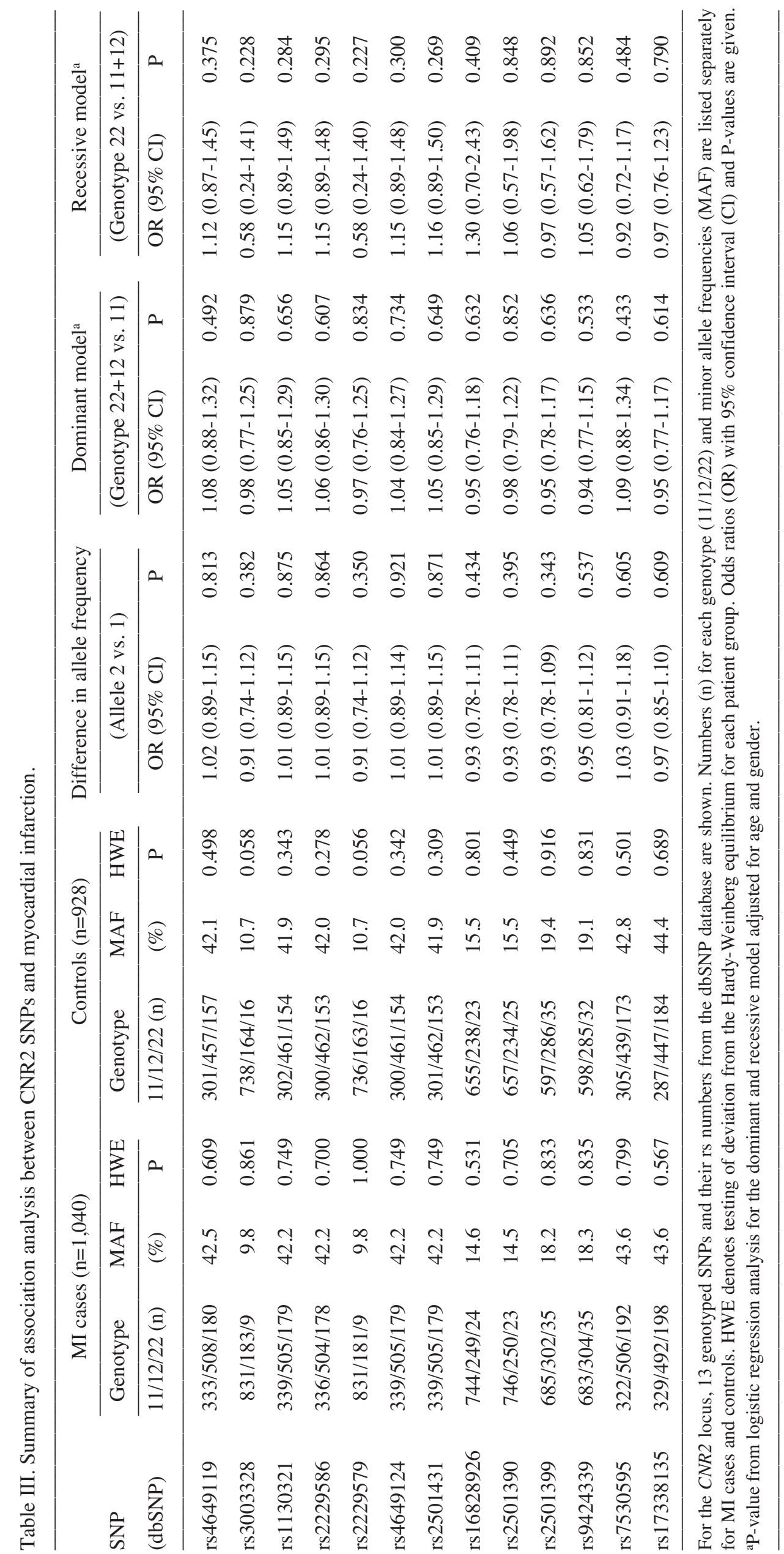




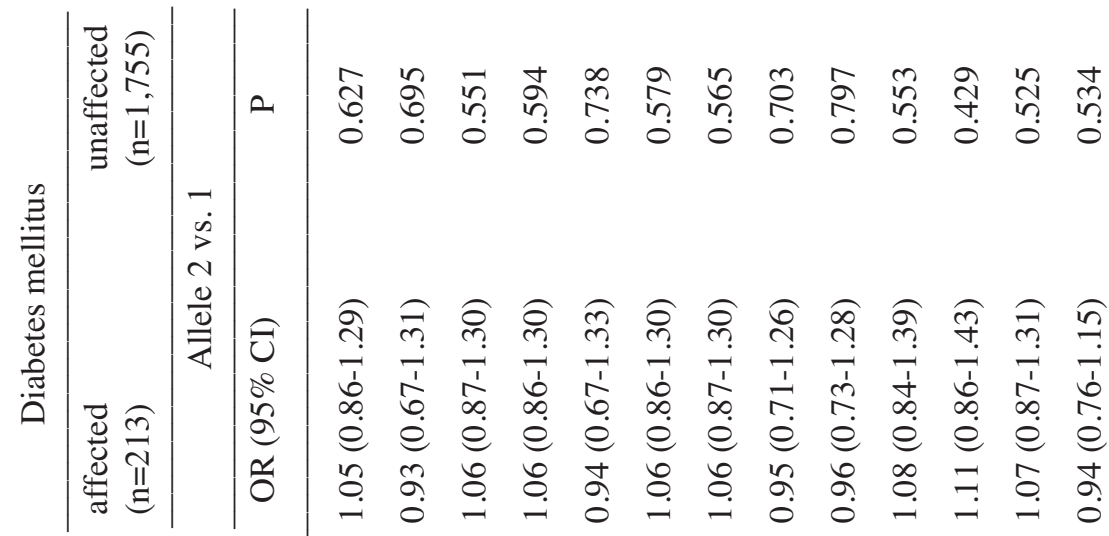

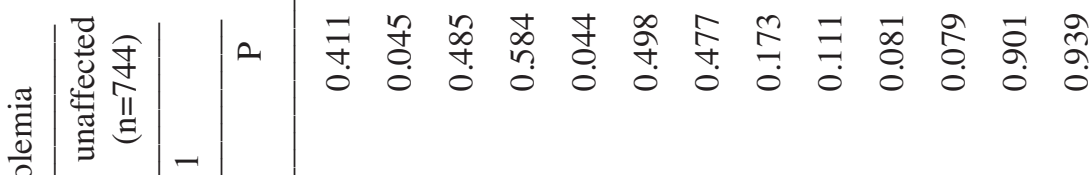

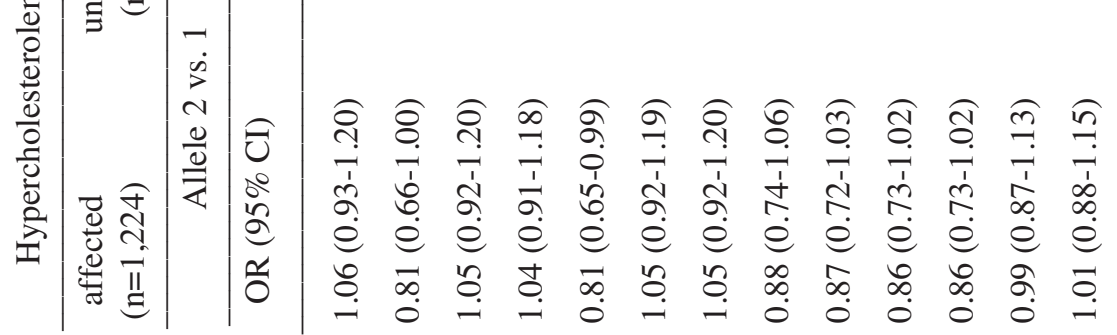

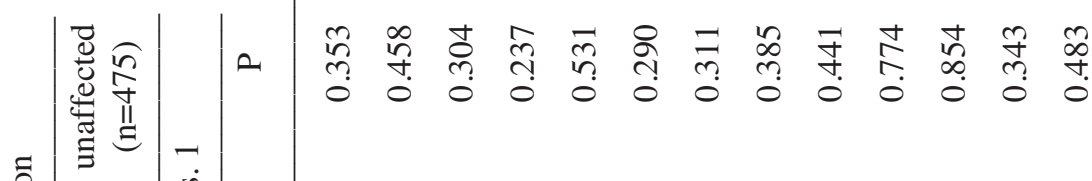

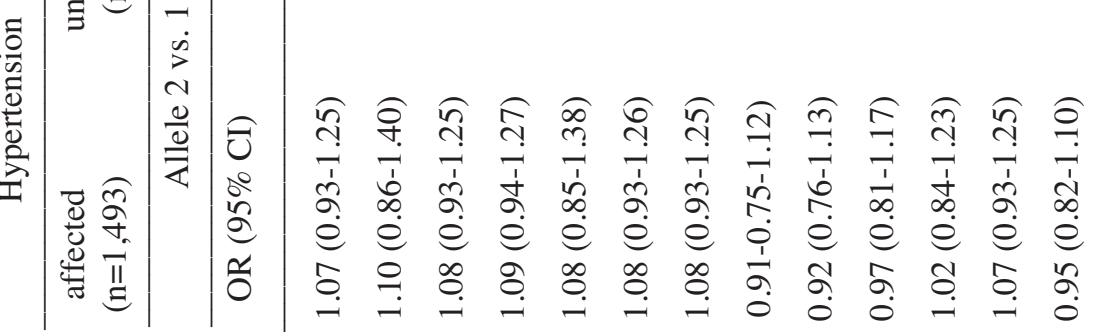

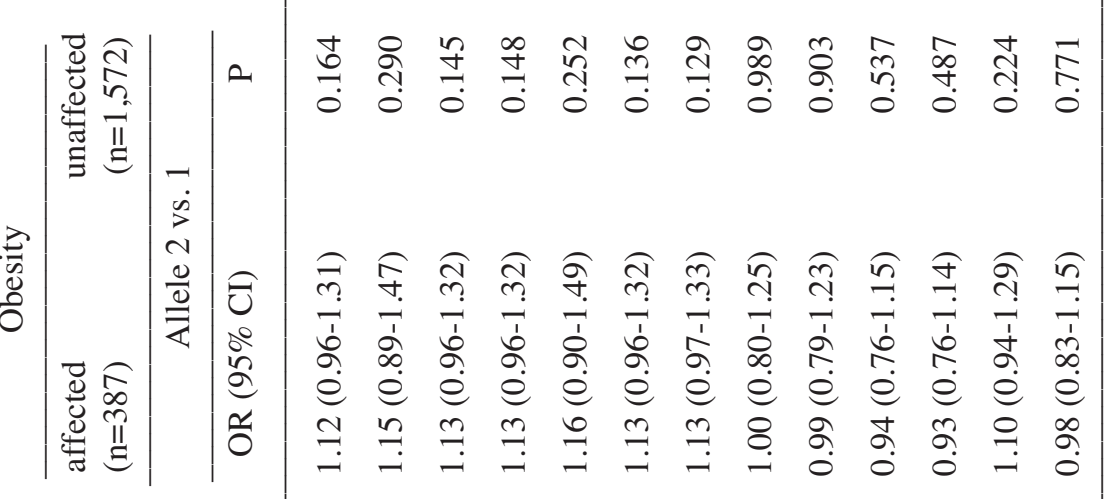




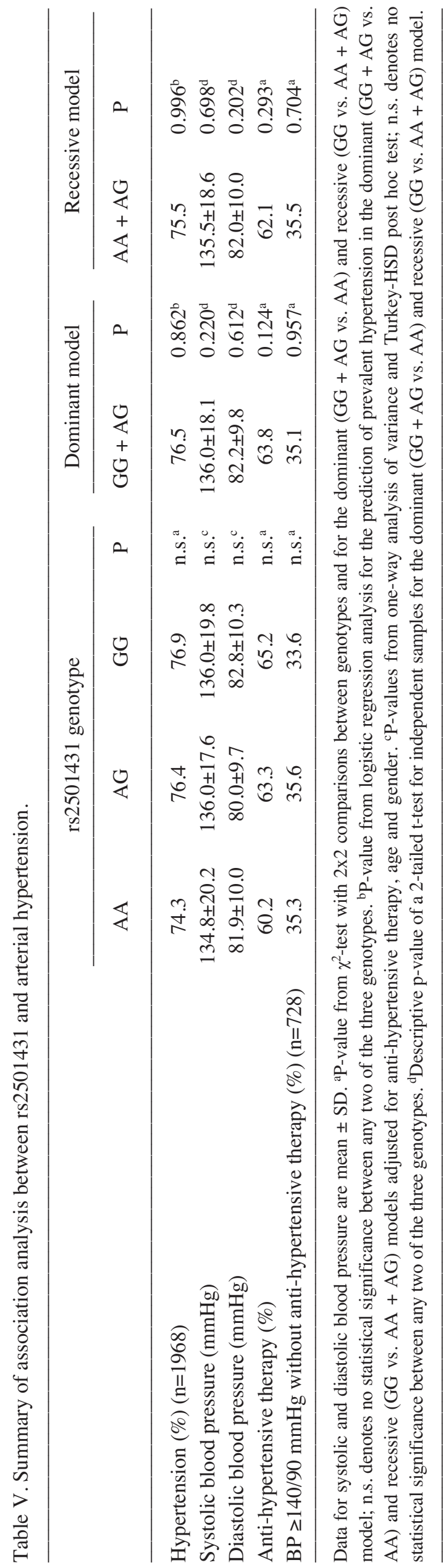

factors such as obesity, arterial hypertension, hypercholesterolemia and diabetes mellitus. However, we found no significant association of common $C N R 2$ sequence variants with MI. Moreover, our results indicate no relevant influence of the investigated $C N R 2$ polymorphisms on classic cardiovascular risk factors. In contrast to the results of Yamada et al where Japanese men without anti-hypertensive therapy carrying the rare GG genotype of rs2501431 demonstrated significantly higher systolic and diastolic blood pressure levels than those with the AA or AG genotype (14), we did not see an association of the exon SNP rs2501431 with prevalent arterial hypertension or systolic and diastolic blood pressure levels in our study population. Besides the varying ethnic background, a possible explanation for this discrepancy may be the different recruitment strategies of the study populations. While Yamada et al examined a population-based cohort randomly selected from residents of two cities in central Japan, our ascertainment approach was to recruit individuals with a strong familial history of CAD from all over Germany with a concomitant accumulation of classic cardiovascular risk factors including arterial hypertension.

Our study has several strengths. Although we report a negative association result, the study is characterized by stringent criteria for study design together with a careful phenotypic and genotypic assessment on the basis of a biologically plausible hypothesis. Furthermore, the candidate gene approach is designed to allow a comprehensive analysis of the complete $C N R 2$ gene region and to largely exclude that a major effect from variations in this gene was missed. Although unbiased large-scale genome-wide association studies using several thousands of SNP markers have only recently become available [and proven to identify genomic regions for susceptibility of complex phenotypes such as CAD and MI (27-29)], they do not fully cover all genes. Specifically, the CNR2 gene is not covered by Illumina HumanHap 300/550 Genotyping BeadChip and Affymetrix GeneChip Human Mapping $500 \mathrm{~K}$ array and might thus escape the attention if tested only with these whole genome arrays.

A possible limitation of the study is the recruitment of our MI patients. We included only patients who survived at least one MI and had another sibling affected with CAD or MI, therefore we have a selection bias for survival of MI and a familial form of the disease. In contrast, however, the familybased character of our selection strategy with its high genetic background enables us to investigate even small genetic effects. Using married-in spouses or their relatives as control subjects minimizes the risk of a population stratification between affected MI patients and unaffected individuals. In addition, the control group was validated as being free from any signs and symptoms of cardiovascular disease including peripheral artery or cerebrovascular disease during the fiveyear follow-up period.

In conclusion, our results suggest that genetic variations in the $C N R 2$ gene have no influence on the risk of MI in a German population. Furthermore, common CNR2 sequence variants are not significantly implicated in the development of classic cardiovascular risk factors, such as arterial hypertension. 


\section{Acknowledgements}

We appreciate the invaluable contribution of participants of the German MI family study. We gratefully acknowledge the excellent technical assistance of Dagmar Glatz, Martina Köhler, Silke Muyrers, Josef Simon and Michaela Vöstner. This study was supported by grants from the National Genome Network (NGFN, 01GS0417), Deutsche Forschungsgemeinschaft (He1921/9-1), the Vaillant-Stiftung (C.H. and H.S.) and the 'Deutsche Stiftung für Herzforschung'. Electronic database information: http://www.ktl.fi/publications/monica/manual/ index.htm, http://www.hapmap.org/, http://www.ncbi.nlm. nih.gov/SNP/ and http://www.broad.mit.edu/mpg/haploview/.

\section{References}

1. Lopez AD, Mathers CD, Ezzati M, Jamison DT and Murray CJ: Global and regional burden of disease and risk factors, 2001: systematic analysis of population health data. Lancet 367 : 1747-1757, 2006.

2. Libby P: Inflammation in atherosclerosis. Nature 420: 868-874, 2002.

3. Hansson GK: Inflammation, atherosclerosis, and coronary artery disease. N Engl J Med 352: 1685-1695, 2005.

4. Mach F: Statins as immunomodulatory agents. Circulation 109: II15-II17, 2004.

5. Libby $\mathrm{P}$ and Aikawa M: Stabilization of atherosclerotic plaques: new mechanisms and clinical targets. Nat Med 8: 1257-1262, 2002.

6. Nilsson J, Hansson GK and Shah PK: Immunomodulation of atherosclerosis: implications for vaccine development. Arterioscler Thromb Vasc Biol 25: 18-28, 2005.

7. Srivastava MD, Srivastava BI and Brouhard B: Delta9 tetrahydrocannabinol and cannabidiol alter cytokine production by human immune cells. Immunopharmacology 40: 179-185, 1998.

8. Yuan M, Kiertscher SM, Cheng Q, Zoumalan R, Tashkin DP and Roth MD: Delta 9-Tetrahydrocannabinol regulates Th1/Th2 cytokine balance in activated human T cells. J Neuroimmunol 133: 124-131, 2002.

9. Lyman WD, Sonett JR, Brosnan CF, Elkin R and Bornstein MB: Delta 9-tetrahydrocannabinol: a novel treatment for experimental autoimmune encephalomyelitis. J Neuroimmunol 23: 73-81, 1989.

10. Malfait AM, Gallily R, Sumariwalla PF, Malik AS, Andreakos E, Mechoulam R and Feldmann M: The nonpsychoactive cannabis constituent cannabidiol is an oral anti-arthritic therapeutic in murine collagen-induced arthritis. Proc Natl Acad Sci USA 97: 9561-9566, 2000

11. Steffens S, Veillard NR, Arnaud C, Pelli G, Burger F, Staub C, Karsak M, Zimmer A, Frossard JL and Mach F: Low dose oral cannabinoid therapy reduces progression of atherosclerosis in mice. Nature 434: 782-786, 2005.

12. Klein TW, Newton C, Larsen K, Lu L, Perkins I, Nong L and Friedman H: The cannabinoid system and immune modulation. J Leukoc Biol 74: 486-496, 2003.

13. Buckley NE, McCoy KL, Mezey E, Bonner T, Zimmer A, Felder CC, Glass $\mathrm{M}$ and Zimmer A: Immunomodulation by cannabinoids is absent in mice deficient for the cannabinoid CB(2) receptor. Eur J Pharmacol 396: 141-149, 2000.

14. Yamada Y, Ando F and Shimokata H: Association of gene polymorphisms with blood pressure and the prevalence of hypertension in community-dwelling Japanese individuals. Int J Mol Med 19: 675-683, 2007.

15. Broeckel U, Hengstenberg C, Mayer B, Holmer S, Martin LJ, Comuzzie AG, Blangero J, Nurnberg P, Reis A, Riegger GA, Jacob HJ and Schunkert H: A comprehensive linkage analysis for myocardial infarction and its related risk factors. Nat Genet 30: 210-214, 2002

16. Sedlacek K, Neureuther K, Mueller JC, Stark K, Fischer M, Baessler A, Reinhard W, Broeckel U, Lieb W, Erdmann J, Schunkert H, Riegger G, Illig T, Meitinger T and Hengstenberg C: Lymphotoxin-alpha and galectin-2 SNPs are not associated with myocardial infarction in two different German populations. J Mol Med 85: 997-1004, 2007.
17. Lieb W, Graf J, Gotz A, Konig IR, Mayer B, Fischer M, Stritzke J, Hengstenberg C, Holmer SR, Doring A, Lowel H, Schunkert $\mathrm{H}$ and Erdmann $\mathrm{J}$ : Association of angiotensinconverting enzyme 2 (ACE2) gene polymorphisms with parameters of left ventricular hypertrophy in men. Results of the MONICA Augsburg echocardiographic substudy. J Mol Med 84: 88-96, 2006

18. Stark K, Neureuther K, Sedlacek K, Hengstenberg W, Fischer M, Baessler A, Wiedmann S, Jeron A, Holmer S, Erdmann J, Schunkert $\mathrm{H}$ and Hengstenberg C: Common Y402H variant in complement factor $\mathrm{H}$ gene is not associated with susceptibility to myocardial infarction and its related risk factors. Clin Sci (Lond) 113: 213-218, 2007

19. Mayer B, Lieb W, Radke PW, Gotz A, Fischer M, Bassler A, Doehring LC, Aherrahrou Z, Liptau H, Erdmann J, Holmer S, Hense HW, Hengstenberg C and Schunkert H: Association between arterial pressure and coronary artery calcification. J Hypertens 25: 1731-1738, 2007.

20. Holmer SR, Hengstenberg C, Mayer B, Doring A, Lowel H, Engel S, Hense HW, Wolf M, Klein G, Riegger GA and Schunkert H: Lipoprotein lipase gene polymorphism, cholesterol subfractions and myocardial infarction in large samples of the general population. Cardiovasc Res 47: 806-812, 2000.

21. Frazer KA, Ballinger DG, Cox DR, Hinds DA, Stuve LL, Gibbs RA, Belmont JW, Boudreau A, Hardenbol P, Leal SM, Pasternak S, Wheeler DA, Willis TD, Yu F, Yang H, Zeng C, Gao Y, Hu H, Hu W, Li C, Lin W, Liu S, Pan H, Tang X, Wang J, Wang W, Yu J, Zhang B, Zhang Q, Zhao H, Zhao H, Zhou J, Gabriel SB, Barry R, Blumenstiel B, Camargo A, Defelice M, Faggart M, Goyette M, Gupta S, Moore J, Nguyen H, Onofrio RC, Parkin M, Roy J, Stahl E, Winchester E, Ziaugra L, Altshuler D, Shen Y, Yao Z, Huang W, Chu X, He Y, Jin L, Liu Y, Shen Y, Sun W, Wang H, Wang Y, Wang Y, Xiong X, Xu L, Waye MM, Tsui SK, Xue H, Wong JT, Galver LM, Fan JB, Gunderson K, Murray SS, Oliphant AR, Chee MS, Montpetit A, Chagnon F, Ferretti V, Leboeuf M, Olivier JF, Phillips MS, Roumy S, Sallee C, Verner A, Hudson TJ, Kwok PY, Cai D, Koboldt DC, Miller RD, Pawlikowska L, Taillon-Miller P, Xiao M, Tsui LC, Mak W, Song YQ, Tam PK, Nakamura Y, Kawaguchi T, Kitamoto T, Morizono T, Nagashima A, Ohnishi Y, Sekine A, Tanaka T, Tsunoda T, Deloukas P, Bird CP, Delgado M, Dermitzakis ET, Gwilliam R, Hunt S, Morrison J, Powell D, Stranger BE, Whittaker P, Bentley DR, Daly MJ, de Bakker PI, Barrett J, Chretien YR, Maller J, McCarroll S, Patterson N, Pe'er I, Price A, Purcell S, Richter DJ, Sabeti P, Saxena R, Schaffner SF, Sham PC, Varilly P, Altshuler D, Stein LD, Krishnan L, Smith AV, Tello-Ruiz MK, Thorisson GA, Chakravarti A, Chen PE, Cutler DJ, Kashuk CS, Lin S, Abecasis GR, Guan W, Li Y, Munro HM, Qin ZS, Thomas DJ, McVean G, Auton A, Bottolo L, Cardin N, Eyheramendy S, Freeman C, Marchini J, Myers S, Spencer C, Stephens M, Donnelly P, Cardon LR, Clarke G, Evans DM, Morris AP, Weir BS, Tsunoda T, Mullikin JC, Sherry ST, Feolo M, Skol A, Zhang H, Zeng C, Zhao H, Matsuda I, Fukushima Y, Macer DR, Suda E, Rotimi CN, Adebamowo CA, Ajayi I, Aniagwu T, Marshall PA, Nkwodimmah C, Royal CD, Leppert MF, Dixon M, Peiffer A, Qiu R, Kent A, Kato K, Niikawa N, Adewole IF, Knoppers BM, Foster MW, Clayton EW, Watkin J, Gibbs RA, Belmont JW, Muzny D, Nazareth L, Sodergren E, Weinstock GM, Wheeler DA, Yakub I, Gabriel SB, Onofrio RC, Richter DJ, Ziaugra L, Birren BW, Daly MJ, Altshuler D, Wilson RK, Fulton LL, Rogers J, Burton J, Carter NP, Clee CM, Griffiths M, Jones MC, McLay K, Plumb RW, Ross MT, Sims SK, Willey DL, Chen Z, Han H, Kang L, Godbout M, Wallenburg JC, L'Archeveque P, Bellemare G, Saeki K, Wang H, An D, Fu H, Li Q, Wang Z, Wang R, Holden AL, Brooks LD, McEwen JE, Guyer MS, Wang VO, Peterson JL, Shi M, Spiegel J, Sung LM, Zacharia LF, Collins FS, Kennedy K, Jamieson R and Stewart J: A second generation human haplotype map of over 3.1 million SNPs. Nature 449: 851-861, 2007.

22. Livak KJ: Allelic discrimination using fluorogenic probes and the 5' nuclease assay. Genet Anal 14: 143-149, 1999.

23. Wigginton JE, Cutler DJ and Abecasis GR: A note on exact tests of Hardy-Weinberg equilibrium. Am J Hum Genet 76: 887-893, 2005.

24. Purcell S, Neale B, Todd-Brown K, Thomas L, Ferreira MA, Bender D, Maller J, Sklar P, de Bakker PI, Daly MJ and Sham PC: PLINK: a tool set for whole-genome association and population-based linkage analyses. Am J Hum Genet 81: 559-575, 2007. 
25. Barrett JC, Fry B, Maller J and Daly MJ: Haploview: analysis and visualization of $\mathrm{LD}$ and haplotype maps. Bioinformatics 21 : 263-265, 2005

26. Karsak M, Cohen-Solal M, Freudenberg J, Ostertag A, Morieux C, Kornak U, Essig J, Erxlebe E, Bab I, Kubisch C, de Vernejoul MC and Zimmer A: Cannabinoid receptor type 2 gene is associated with human osteoporosis. Hum Mol Genet 14: 3389-3396, 2005 .

27. Helgadottir A, Thorleifsson G, Manolescu A, Gretarsdottir S, Blondal T, Jonasdottir A, Jonasdottir A, Sigurdsson A, Baker A, Palsson A, Masson G, Gudbjartsson DF, Magnusson KP, Andersen K, Levey AI, Backman VM, Matthiasdottir S, Jonsdottir T, Palsson S, Einarsdottir H, Gunnarsdottir S, Gylfason A, Vaccarino V, Hooper WC, Reilly MP, Granger CB, Austin H, Rader DJ, Shah SH, Quyyumi AA, Gulcher JR, Thorgeirsson G, Thorsteinsdottir U, Kong A and Stefansson K: A common variant on chromosome 9p21 affects the risk of myocardial infarction. Science 316: 1491-1493, 2007.
28. McPherson R, Pertsemlidis A, Kavaslar N, Stewart A, Roberts R, Cox DR, Hinds DA, Pennacchio LA, Tybjaerg-Hansen A, Folsom AR, Boerwinkle E, Hobbs HH and Cohen JC: A common allele on chromosome 9 associated with coronary heart disease. Science 316: 1488-1491, 2007.

29. Samani NJ, Erdmann J, Hall AS, Hengstenberg C, Mangino M, Mayer B, Dixon RJ, Meitinger T, Braund P, Wichmann HE, Barrett JH, Konig IR, Stevens SE, Szymczak S, Tregouet DA, Iles MM, Pahlke F, Pollard H, Lieb W, Cambien F, Fischer M, Ouwehand W, Blankenberg S, Balmforth AJ, Baessler A, Ball SG, Strom TM, Braenne I, Gieger C, Deloukas P, Tobin MD, Ziegler A, Thompson JR and Schunkert H: Genomewide association analysis of coronary artery disease. N Engl J Med 357: 443-453, 2007. 